\title{
Construct Validity of the Two Safety Culture Questionnaires
}

\author{
Paz de Oliveira SK, Araújo Girão AL and Fontenele Lima de Carvalho RE* \\ Ceara State University, Brazil
}

*Corresponding author: Rhanna Emanuela Fontenele Lima de Carvalho, Dr. Silas

Munguba Ave, 1700. Fortaleza, Ceará, Brazil, Tel: +55 85 3101-9806;

Email: rhanna.lima@uece.br

\section{Abstract}

Objective: The aim of the study was to validate the construct of two culture assessment instruments adapted and validated for the Portuguese language, the Safety Attitudes Questionnaire (SAQ) and the Hospital on Patient Safety Culture (HSOPSC).

Material and Methods: Cross-sectional, exploratory-descriptive study with quantitative approach. The two instruments were applied at the same time to all professionals working in intensive care units that met the inclusion criteria: working at least 20 hours per week and at least one month in the sector.

Results: 170 questionnaires were distributed and 127 were considered valid for the research. The professionals that participated in the study, 60 (75\%) were female, most had between 1 and 5 years of time in unit 40 (50\%), with institution 39 (49\%) and workload between 20 and 39 hours per week 32 (40\%). Still, 69 (86.3\%) reported having direct contact with the patient. Regarding the validation results, we observed positive and statistically significant correlations between SAQ domains with four HSOPSC domains. In the regression analysis, all domains of the SAQ, except for Stress Perception, explained all the variables resulting from HSOPSC.

Conclusion: Based on this study it was concluded that both instruments are valid and reliable for the evaluation of safety culture. However, it is worth emphasizing that the two instruments present factors that facilitate and hinder the application of the same.

Keywords: Nursing; Intraclass; Safety

Abbreviations: SAQ: Safety Attitudes Questionnaire; HSOPSC: Hospital on Patient Safety Culture; ICC: Intraclass Correlation Coefficient; AHRQ: American Agency for Quality in Health.

\section{Introduction}

Safety culture is increasingly recognized as an important strategy and precursor needed to improve patient safety. According to the United States Institute of Medicine, safety culture can be defined as an individual and organizational behavior that continually seeks to establish a commitment to the safety and quality of services provided [1].

The first step in implementing an institution's safety culture is to evaluate it. Assessing safety culture in health facilities can reveal conditions in a work environment that lead to adverse events. This evaluation can be performed soon after interventions aimed at patient safety and as a method of monitoring the effectiveness of these interventions, in addition to increasing the awareness of professionals and patients about safety issues. 


\section{Nursing \& Healthcare International Journal}

In Brazil, there are two safety culture assessment instruments translated and adapted for the Portuguese language, the Safety Attitude Questionnaire (SAQ) and the Hospital on Patient Safety Culture (HSOPSC). These two instruments are the most applied in the world for this purpose, as well as being the only safety culture evaluation instruments translated and adapted to the Portuguese language [2-4].

SAQ was built in the United States by researchers at the University of Texas, Center of Excellence for Patient Safety and has been applied in more than 500 hospitals in the United States, United Kingdom and New Zealand. This instrument has 41 items distributed on a single page and measures the perception of health professionals through six domains: Team Work Climate, Safety Climate, Job Satisfaction, Stress Perception, Management Perception, Working Conditions [2].

HSOPSC was developed and made available by the US Agency for Research and Quality of Health (AHRQ) in 2004 [5] and translated and validated for Brazil in 2013 [4], and organizational norms, reporting of adverse events, communication, supervision and management. The HSOPSC contains 50 items distributed in 12 points in item scale [5]. Since the items were written in both directions as positive and negative, the written items were partially reversed.

The validation process of a validation instrument during cross-cultural adaptation concluded that, unlike the validation process, the evidence was repeated at various times, evidencing the importance of a continuous evaluation of the instruments, since the two are reference tools for assessing safety culture.

Construct validity is based on what is really thought about the median measures. The necessary evidence for this type of evaluation can be obtained from the internal analysis of the instrument, through confirmatory factor analysis, internal consistency and its correlations with other testicles, by the preference that they are accepted as construct measures. The higher the correlations are, the more the test will be the measurement sense of the construct in question [6].

Given the availability of two instruments in the Portuguese language that evaluates the same construct, but with different characteristics, which seeks to answer as the main research questions: Is the SAQ domain convergent to the same constructs and evaluated by the HSOPSC domains? As predictive variables (domains) they explained as a result. In this sense, the Safety Study
Questionnaire (SAQ) and the Hospital on Patient Safety Culture (HSOPSC).

\section{Materials and Methods}

Cross-sectional, exploratory-descriptive study with quantitative measures in intensive care units of two hospitals in Brazil. The hospitals that participated in the study were part of a larger study evaluating the culture of Brazilian hospitals [7]. The construct validation handles, the two instruments were distributed to all individuals working in the intensive care units of the hospitals participating in the study, corresponding to a sample of 170 professionals. However, 127 returned the completed instruments. The study included nurses, physicians, nursing assistants, physiotherapists, nutritionists, psychologists, pharmacists and social workers who met the inclusion criteria: less than 20 hours a week and less than a month in the sector.

Data were collected through the Safety Attitude Questionnaire (SAQ) and the Hospital on Patient Safety Culture (HSOPSC), both translated and validated for Brazil, as well as a sociodemographic characterization form. One answer to each question is a 5-point scale, including the final variation of 100 , with a cut-off point of 752. The HSOPSC covers 12 dimensions of the safety culture in various sizes. It contains 50 items in total; 44 are related to safety culture and 6 items are related to personal information [4].

The study participants signed and received the Informed Consent Term. The instruments were filled in the working environment available on paper. The study was approved by the Ethics Committee of the institutions and has protocol number 985.564. All participants in the study signed the informed consent form and were guaranteed anonymity.

The collected data were inserted into a database and then processed in the R software. Each questionnaire had its results converted into scores according to the value established for each option.

To make this comparison possible, the HSOPSC scores were normalized according to the SAQ score. The calculation of the Intraclass Correlation Coefficient (ICC) was applied to evaluate the correlation between the domains, and the mixed two way model was chosen, with a 95\% confidence interval. The interpretation of ICC values was based on the scale of values suggested by 
Menz, et al. [8,9], which are: greater than 0.75 are considered excellent; values between $0.40-0.75$ are moderate and / or satisfactory and values below 0.40 are unsatisfactory. The reliability of the instruments was measured by Cronbach's alpha and was considered 0.69, the lower limit generally accepted in exploratory research. To understand how much each predictive variable (domains) explained the outcome variables, the Regression Analysis was performed. The following variables were considered: Number of events reported in the last 12 months (Section D), Patient Safety Grade
(Section E) and Overall Perceptions of Patient Safety (A10, A15, A17 e A18).

\section{Results}

For the validation of construct, the two instruments were applied at the same time, being answered by 127 professionals. Of these, 68 (75\%) professionals were female, with 1 to 5 years of time in unit 59 (46.5\%) and with a workload of 20 to 60 hours per week $99(60 \%)$. Still, 115 (90.6\%) professionals reported having direct contact with the patient (Table 1).

\begin{tabular}{|c|c|c|c|}
\hline \multicolumn{2}{|l|}{ Variable } & $\mathbf{n}$ & $\%$ \\
\hline \multirow{4}{*}{ Gender } & female & 68 & 75 \\
\hline & male & 54 & 22,5 \\
\hline & missing data & 5 & 2,5 \\
\hline & Total & 127 & 100 \\
\hline \multirow{7}{*}{ How long have you worked in your current hospital work area/unit } & Less than 1 year & 27 & 21,3 \\
\hline & 1 to 5 years & 59 & 46,5 \\
\hline & 6 to 10 years & 23 & 18,1 \\
\hline & 11 to 15 years & 9 & 7,1 \\
\hline & 16 to 20 years & 4 & 3,1 \\
\hline & 21 years or more & 5 & 3,9 \\
\hline & Total & 127 & 100 \\
\hline \multirow{8}{*}{ Hours per week } & Less than 20 hours per week & 8 & 6,3 \\
\hline & 20 to 39 hours per week & 50 & 39,4 \\
\hline & 40 to 59 hours per week & 49 & 38,6 \\
\hline & 60 to 79 hours per week & 13 & 10,2 \\
\hline & 80 to 99 hours per week & 2 & 1,6 \\
\hline & 100 hours per week or more & 2 & 1,6 \\
\hline & missing data & 3 & 3,8 \\
\hline & Total & 127 & 100 \\
\hline \multirow{4}{*}{ Interaction or contact with patient } & Yes & 115 & 90,6 \\
\hline & No & 7 & 5,5 \\
\hline & Missing data & 5 & 3,9 \\
\hline & Total & 127 & 100 \\
\hline
\end{tabular}

Table 1: Characterization of the subjects of the research.

As for the general scores of the two instruments, mean values ranged from 50 to 74.1 (SAQ) and 42.8 to 60.9 (HSOPS). For the SAQ, it is expected for a positive safety culture, scores above 75, thus considering that instrument was not observed any domain with scores above this value. However, for the HSOPSC we consider positive responses, that is, responses above $50 \%$ of partially and totally agree for each domain. According to this criterion, five of the ten HSOPSC domains presented positive responses $>50 \%$, indicating that they are strong factors and are present in the safety culture in the studied unit (Table 2). 


\section{Nursing \& Healthcare International Journal}

\begin{tabular}{|c|c|c|c|c|c|}
\hline & Patient Safety Culture Composite & mean & SD* & $\begin{array}{c}\text { Positive } \\
\text { porcetagem* }\end{array}$ & $\begin{array}{c}\text { Cronbach } \\
\text { Alfa }\end{array}$ \\
\hline HSOPSC & $\begin{array}{c}\text { Supervisors/managers consider staff suggestions for } \\
\text { Actions Promoting Patient Safety }\end{array}$ & 42.8 & 14.6 & 61 & 0.76 \\
\hline HSOPSC & Organizational Learning-Continuous Improvement & 60.9 & 17.7 & 57 & 0.51 \\
\hline HSOPSC & Teamwork within Units & 57.8 & 17.5 & 53 & 0.68 \\
\hline HSOPSC & Feedback and Communication About Error & 52.8 & 20.3 & 50 & 0.51 \\
\hline HSOPSC & Communication Openness & 51.2 & 15.8 & 51 & 0.62 \\
\hline HSOPSC & Nonpunitive Response to Error & 60.5 & 17 & 17 & 0.37 \\
\hline HSOPSC & Management Support for Patient Safety & 48.8 & 15.6 & 48 & 0.65 \\
\hline HSOPSC & Handoffs and Transitions & 43.7 & 20.5 & 44 & 0.78 \\
\hline HSOPSC & Teamwork Across Units & 70 & 17.3 & 36 & 0.71 \\
\hline HSOPSC & Staffing & 49.3 & 15.6 & 46 & 0.33 \\
\hline SAQ & Teamwork Climate & 50 & 11.9 & 77 & 0.71 \\
\hline SAQ & Safety Climate & 74.1 & 17.6 & 56.2 & 0.65 \\
\hline SAQ & Job satisfaction & 72.9 & 27.2 & 70 & 0.73 \\
\hline SAQ & Stress recognition & 50.1 & 22 & 33 & 0.84 \\
\hline SAQ & Perceptions of management units & 53.7 & 24 & 40 & 0.8 \\
\hline SAQ & Perceptions of management hospital & 65.8 & 24.3 & 61 & 0.74 \\
\hline SAQ & Working condition & & 0.73 \\
\hline
\end{tabular}

Table 2: Presentation of mean scores and internal consistency of HSOPSC and SAQ domains.

*The positive responses refer to the sum of I agree totally and agree partially divided by the number of responses (neutral, totally and partially disagree except the absent data). SD: Standard Deviation

Regarding the internal consistency analysis, the SAQ presented good reliability, except for the Safety Climate domain, while the HSOPSC showed two domains with Alpha above 0.7 (Table 2).
Regarding the Infraclass Correlation Coefficient, SAQ presented significant ICC 0.63 for all domains, considering moderate to excellent reproducibility. The HSOPSC showed ICC ranging from 0.33 to 0.91 significant for six domains and reproducibility ranging from poor to excellent (Table 3).

\begin{tabular}{|c|c|c|c|}
\hline & Patient Safety Culture Composite & ICC & Anova \\
\hline SAQ & Teamwork climate & 0.68 & $<0.05$ \\
\hline SAQ & Safety Climate & 0.63 & $<0.05$ \\
\hline SAQ & Job satisfaction & 0.67 & $<0.05$ \\
\hline SAQ & Stress recognition & 0.84 & $<0.05$ \\
\hline SAQ & Perceptions of management units & 0.78 & $<0.05$ \\
\hline SAQ & Perceptions of management hospital & 0.76 & $<0.05$ \\
\hline SAQ & Working condition & 0.72 & $<0.05$ \\
\hline HSOPSC & Supervisors/managers consider staff suggestions for Actions Promoting & 0.75 & $<0.05$ \\
\hline HSOPSC & Patient Safety & 0.46 & $<0.05$ \\
\hline HSOPSC & Organizational Learning-Continuous & 0.59 & $<0.05$ \\
\hline HSOPSC & Teamwork within Units & 0.5 & $<0.05$ \\
\hline HSOPSC & Feedback and Communication About Error & 0.59 & $<0.05$ \\
\hline
\end{tabular}




\section{Nursing \& Healthcare International Journal}

\begin{tabular}{|c|c|c|c|}
\hline HSOPSC & Nonpunitive Response to Error & 0.36 & NS$^{*}$ \\
\hline HSOPSC & Management Support for Patient Safety & 0.65 & NS* $^{*}$ \\
\hline HSOPSC & Handoffs and Transitions & 0.77 & $<0.05$ \\
\hline HSOPSC & Teamwork Across Units & 0.53 & $<0.05$ \\
\hline HSOPSC & Staffing & 0.33 & NS* $^{*}$ \\
\hline HSOPSC & Number of Events Reported & 0.91 & NS$^{*}$ \\
\hline HSOPSC & Patient Safety Grade & 0.38 & $<0.05$ \\
\hline
\end{tabular}

Table 3: Intraclass coefficient and ANOVA of the domains.

*NS-not significant

For construct validation, we considered the significant correlations between the domains of the two instruments, that is, the degree to which the measures of two instruments are related positively. Thus, when the domains of the two instruments were correlated, it was observed that almost all SAQ domains correlated with four domains and with all the variables resulting from HSOPSC (Table 4). The only domain of SAQ that did not correlate with any HSOPSC domain was Stress perception.

\begin{tabular}{|c|c|c|}
\hline Domains SAQ & Domains HSOPSC & Outcome variables \\
\hline Teamwork climate & $\begin{array}{c}\text { Teamwork within Units, Organizational Learning- } \\
\text { Continuous, Feedback and Communication About } \\
\text { Error }\end{array}$ & $\begin{array}{l}\text { Patient Safety Grade and Number of } \\
\text { Events Reported }\end{array}$ \\
\hline Safety climate & $\begin{array}{l}\text { Organizational Learning-Continuous e Feedback } \\
\text { and Communication About Error }\end{array}$ & $\begin{array}{l}\text { Patient Safety Grade, Overall } \\
\text { Perceptions of Patient Safety and } \\
\text { Number of Events Reported }\end{array}$ \\
\hline Job satisfaction & - & Number of Events Reported \\
\hline $\begin{array}{c}\text { Perceptions of } \\
\text { management units }\end{array}$ & Teamwork within Units & Patient Safety Grade \\
\hline $\begin{array}{l}\text { Perceptions of } \\
\text { management } \\
\text { hospital }\end{array}$ & $\begin{array}{l}\text { Organizational Learning-Continuous e Feedback } \\
\text { and Communication about Error e Management } \\
\text { Support for Patient Safety }\end{array}$ & Number of Events Reported \\
\hline Working condition & Management Support for Patient Safety & Patient Safety Grade \\
\hline
\end{tabular}

Table 4: Correlation between SAQ and HSOP domains.

To understand how much each predictive variable (domains) explained the outcome variables (Number of events reported in the last 12 months, Patient Safety Grade and Overall Perceptions of Patient Safety) was performed the Regression analysis. It was observed that the SAQ predictive variables explained between 22 and
$33 \%$ of the variables: Number of events reported, Patient Safety Grade and Overall Perceptions of Patient Safety with statistical significance, while HSOPSC explained two variables: Patient Safety Grade and Overall Perceptions of Patient Safety (Table 5). 


\section{Nursing \& Healthcare International Journal}

\begin{tabular}{|c|c|c|c|}
\hline \multirow{2}{*}{ Predictive variable } & \multicolumn{3}{|c|}{ Outcome variable } \\
\cline { 2 - 4 } & $\begin{array}{c}\text { Number of } \\
\text { Events } \\
\text { Reported }\end{array}$ & $\begin{array}{c}\text { Patient Safety } \\
\text { Grade }\end{array}$ & $\begin{array}{c}\text { Overall } \\
\text { Perceptions of } \\
\text { Patient Safety }\end{array}$ \\
\hline Teamwork climate & $0.35(0.01)$ & $0.34(<0.01)$ & \\
\hline Safety climate & $0.46(0.01)$ & $0.36(<0.01)$ & \\
\hline Job satisfaction & $0.32(0.01)$ & & \\
\hline Perceptions of management hospital & $0.31(<0.05)$ & $0.35(<0.05)$ & \\
\hline Working condition & & $0.36(<0.05)$ & \\
\hline $\begin{array}{c}\text { Organizational Learning- } \\
\text { Continuous }\end{array}$ & - & & $0.37(<0.05)$ \\
\hline Nonpunitive Response to Error & - & & $0.49(<0.05)$ \\
\hline Handoffs and Transitions & - & & $0.24(<0.05)$ \\
\hline
\end{tabular}

Table 5: Regression analysis of predictive variables and outcome.

\section{Discussion}

The characterization of the professionals who participated in the study is similar to the results of other studies that showed the female gender as the predominant gender $[10,11]$, who have been working for at least five years in the institution [12], with a weekly workload of 20-60 hours and with direct contact with the patient $[10,12,13]$. Gender is not a factor that can be associated with results in the safety culture. However, work experience time and the link with the institution indicate that health professionals are very knowledgeable about their work and may have positive safety attitudes [14].

The mean scores of the HSOPSC domains ranged from 42.8 to 70 on a scale of 0 to 100 . Of note were the domains, Teamwork with the highest average and Expectations and actions to promote the safety of supervisors and managers with the lowest average. These results diverge, in part, from the data identified in the report of the American Agency for Quality in Health (AHRQ), which, after applying this instrument to thousands of health professionals, showed that the teamwork in the units presented a better result and a non-punitive response the error was the one that presented the worst result [7]. This domain was also the one with the lowest percentage of positive responses in other studies emphasizing that the actions of supervisors and managers considering the employees' suggestions for improving patient safety is still a failure in the institutions studied [15-17]. The results of SAQ are similar to those identified in the studies with this instrument in which they present the domain Satisfaction in the Work as the best evaluated and the domain Management perception as the domain of unfavorable evaluation $[10,18,19]$.
Health institutions committed to patient safety policies can improve nurses' job satisfaction by developing the quality of their work. It is considered that the leadership styles of the supervisors and managers can imply in opposite effect, reducing the autonomy and suppressing the professional satisfaction of the nurses. To avoid this, hospital managers must demonstrate positive attitudes in order to promote patient safety and professional satisfaction $[20,21]$.

Internal consistency analysis using Cronbach's Alpha presented similar results to other studies in relation to the domains of SAQ and HSOPSC [4,22-24]. The degree of reproducibility of the SAQ (ICC> 0.63 ) was moderate to excellent, which means that the variation between the professionals' responses to this instrument was small.

For construct validation, we considered the significant correlations between the domains of the two instruments, that is, the degree to which the measures of two instruments are related positively [5]. Thus, a positive association was observed between six SAQ domains with four domains and all variables resulting from HSOPSC. The only domain of SAQ that showed no correlation was Stress perception. This means that the two instruments can evaluate similar constructs and can be used before and after interventions that improve outcomes for the patient.

In general, the ICC of the domains presented statistically significant correlations. (SAQ), Work Conditions (SAQ), Supervisor Safety Promotion Expectations and Actions (HSOPSC), Pass on duty (HSOPSC) and reported (HSOPSC) presented a statistically 


\section{Nursing \& Healthcare International Journal}

significant association, considered excellent reproducibility.

The domain Teamwork Climate (SAQ) was significantly correlated with five HSOPSC domains, namely: Learning, Teamwork of the unit, Feedback, Degree of safety and Frequency of reported events. This correlation makes sense since good quality of the relationship and collaboration among team members occurs when there are positive changes and learning from the reported events, when team members support each other, treat each other with respect and work together as a team. The other HSOPSC domains had positive correlations for one or two SAQ domains. Similar results were identified in the study by Etchegaray and Thomas [25] that demonstrated the predictive reliability and validity in both SAQ and HSOPSC instruments.

The regression analysis allowed us to understand how much each predictive variable (domains) explains the outcome variables. The three HSOPSC variables explained all SAQ domains, with emphasis on the domains of Safety, Teamwork Climate, Work Satisfaction and Hospital Management Perception that were explained by all outcome variables. While two variables result General Degree of Security and General Perception of Security, they explained HSOPSC domains.

The evaluation of the reliability and validity of the two instruments was consistent with previous studies that evaluated the psychometric characteristics of the two instruments $[3,4,25]$. However, this was the first construct validation survey with the two brazilian instruments that evaluate safety culture, so it is emphasized the need for more research with additional safety culture results to elucidate the strengths and weaknesses of the two instruments. It was observed that almost all domains of SAQ are correlated with some domains of HSOPSC and all variable outcomes. In addition, all variables resulting from the HSOPSC explain the domains of the SAQ.

\section{Conclusion}

It was concluded that both instruments are valid and reliable for evaluating the safety culture. It is worth emphasizing that the two instruments present factors that facilitate and hinder their application. The SAQ has a single page and has been evaluated by health professionals as a quick and practical tool to fill out, but does not have outcome evaluation items and suggestions space. The HSOPSC is a long six-page instrument, a characteristic identified as an impeding factor by many professionals, reflecting the low adherence of professionals in this study. It should be highlighted that this instrument presents variables that allow the evaluation of results, indicators that can complement and confirm the evaluated constructs. In addition to possessing a space for the writing of suggestions. The two culture evaluation questionnaires available in the Portuguese language can be useful tools in the initial diagnosis of the institution's safety culture and assist managers in decision making.

\section{References}

1. Kohn LT, Corrigan JM, Donaldson MC (2000) To Err is Human: building a safer health system. Committee on Quality of Health Care, Institute of Medicine, National Academy Press Washington (DC).

2. Sexton JB, Helmreich RL, Neilands TB, Rowan K, Vella $\mathrm{K}$, et al. (2006) The Safety Attitudes Questionnaire: psychometric properties, benchmarking data, and emerging research. BMC Health Serv Res 6: 44.

3. Carvalho REFL, Cassiani SHB (2012) Cross-cultural adaptation of the Safety Attitudes QuestionnaireShort Form 2006 for Brazil. Revista Latino-Americana de Enfermagem 20(3): 575-582.

4. Reis CT, Martins M, Laguardia J (2012) Transcultural adaptation of the Brazilian version of the Hospital Survey on Patient Safety Culture: initial stage. Cad Saúde Pública, Rio de Janeiro 28(11): 2199-2210.

5. Agency for Healthcare Research and Quality (2015) Hospital Survey on Patient Safety Culture: 2004. User comparative database Report, AHRQ.

6. Sternick C (2017) Technical characteristics of a measuring instrument. Arquivos Brasileiros de Psicologia Aplicada 28 (1): 48-67.

7. Carvalho RE, Arruda LP, Birth NK, Sampaio RL, Cavalcante ML, et al. (2017) Assessment of the safety culture in public hospitals in Brazil. Rev Lat Am Nursing 25: e2849.

8. Menz HB, Latt MD, Tiedemann A, Mun San Kwan M, Lord SR (2004) Reliability of the GAITRite walkway system for the quantification of temporal spatial parameters of gait in young and older people. Gait Posture 20(1): 20-25.

9. Hair JF, William B, Babin B, Anderson RE (2009) Multivariate data analysis $7^{\text {th }}$ (Edn.), Porto Alegre: Bookman, pp: 1-734. 


\section{Nursing \& Healthcare International Journal}

10. Rigobello MCG, Carvalho REFL, Guerreiro JM, Motta APG, Atila E, et al. (2017) The perception of the patient safety climate by professionals of the emergency department. Int Emerg Nurs 33: 1-6.

11. Zimmermann N, Küng K, Sereika SM, Engberg S, Sexton B, et al. (2013) Assessing the safety attitudes questionnaire (SAQ), German language version in Swiss university hospitals-a validation study. BMC Health Serv Res 13: 347.

12. Santiago TH, Turrini RN (2015) Organizational culture and climate for patient safety in Intensive Care Units. Rev Esc Enferm USP 49: 123-130.

13. Najjar S, Hamdan M, Baillien E, Vleugels A, Euwema M, et al. (2013) The Arabic version of the hospital survey on patient safety culture: a psychometric evaluation in a Palestinian sample. BMC Health Serv Res 13: 193.

14. Bodur S, Filiz E (2010) Validity and reliability of Turkish version of Hospital Survey on Patient Safety Culture and perception of patient safety in public hospitals in Turkey. BMC Health Services Research 10: 28.

15. Kings CT (2013) The safety culture of the patient: validation of a measurement instrument for the Brazilian hospital context [thesis]. Rio de Janeiro (RJ): National School of Public Health.

16. Chen IC, Li HH (2010) Measuring patient safety culture in Taiwan using the Hospital Survey on Patient Safety Culture (HSOPSC). BMC Health Serv Res 10: 152.

17. Dolci GF, Suárez JR, Casanova HA, Fernández CR, Torres FH, et al. (2010) Culture about patient safety in health professionals. Cir Cir 78(6): 527-532.
18. Brasaite I, Kaunonen M, Martinkenas A, Suominen T (2016) Health care professionals' attitudes regarding patient safety: cross-sectional survey. BMC Research Notes 9: 177.

19. Nguyen G, Gambashidze N, Ilyas SA, Pascu D (2015) Validation of the safety attitudes questionnaire (short form 2006) in Italian in hospitals in the northeast of Italy. BMC Health Services Research 15: 284.

20. Inoue T, Karima R, Harada K (2017) Bilateral effects of hospital patient-safety procedures on nurses' job satisfaction. Int Nurs Rev 64(3): 437-445.

21. Weng SJ, Kim SH, Wu CL (2017) Underlying influence of perception of management leadership on patient safety climate in healthcare organizations-A mediation analysis approach. Int J Qual Health Care 29(1): 111-116.

22. Carvalho PA, Göttems LB, Pires MR, de Oliveira ML (2015) Safety culture in the operating room of a public hospital in the perception of healthcare professionals. Rev Lat Am Nursing 23(6): 1041-1048.

23. Aymen E, Akbarisari A, Rashidian A, Aljeesh Y, Radwan M, et al. (2017) Psychometric Properties of an Arabic Safety Attitude Questionnaire. Oman Med J 32(2): 115-123.

24. Perneger TV, Staines A, Kundig F (2014) Internal consistency, factor structure and construct validity of the French version of the Hospital Survey on Patient Safety Culture. BMJ Qual Saf 23(5): 389-397.

25. Etchegaray JM, Thomas E (2012) Comparing two safety culture surveys: Safety Attitudes Questionnaire and Hospital Survey on Patient Safety. BMJ Qual Saf 21(6): 490-498. 